\title{
A Comparative Assessment of Various Turbulence Models Applied for Simulation of Air-Water Flow Over Chute Spillway
}

\author{
Saeed Shayanseresht ${ }^{1 *}$, Mohammad Manafpour ${ }^{1}$ \\ ${ }^{1}$ Department of Civil Engineering, Urmia University, 5756151818 Urmia, Iran \\ * Corresponding author, e-mail: s.shayanseresht@gmail.com
}

Received: 13 February 2021, Accepted: 01 August 2021, Published online: 16 August 2021

\begin{abstract}
Chute aerators have been largely used to reduce cavitation hazard in high head spillways. There is no definite turbulence model for simulating these devices in smooth spillways in spite of its importance in critical conditions. A simulation in two-phase air-water chute flow and its aerator with five different turbulence models (RNG, Standard and Realizable $k-\varepsilon$ Models, SST and Standards $k-\omega$ Models) has been numerically investigated by Fluent software. Finite Volume and VOF methods were used for discretization of flow equations and free surface modeling. Flow depth, velocity and bottom pressure comparison were made along with the air cavity length determination by numerical, experimental and reference equations. The best model with the minimum value of error percentage for flow depth and velocity was RNG $k-\varepsilon$ turbulence model. The realizable and RNG $k-\varepsilon$ turbulence models showed better results for the pressure head at the bottom of the chute. The RNG $k-\varepsilon$ model results for the jet length have a very slight difference with the experimental results. The length of the cavity is closely associated with the flow emergence angle $\theta^{\prime}$ over aerators. The bottom air concentration of spillway chute simulated by all the turbulence models, except for the RNG $k-\varepsilon$ model, can be overestimated and therefore may affect the designing of aerator geometry.
\end{abstract}

Keywords

spillway, chute aerator, air concentration, turbulence models, jet length

\section{Introduction}

Spillways are among the major hydraulic structures used for dam safety. A spillway aerator is employed for artificial air-entraining and preventing the cavitation on concrete surfaces exposed to flows with high-velocity [1]. For example, in case the index of cavitation decreases to a value below a certain threshold and the flow velocity of water exceeds $25 \mathrm{~m} / \mathrm{s}$, cavitation may cause damages to the chute bottom leading to adverse effects for the spillway safety [2]. The damages caused by cavitation must be prevented as the intensity of cavitation on a damaged spillway structure increases during the time. Thus, engineering design aims to protect spillways against destruction by cavitation. Perhaps the only economic countermeasure for this purpose is to use an aerator. The task of an aerator is to alleviate the negative pressure near the bottom of the chute, entraining air into the high-speed flow, and thereby, avoiding the cavitation risk. The deflected flow jet surrounds an air cavity downstream of an aerator. The air entrainment occurs at the lower nappe of the jet where the turbulence intensity is high. Airflow is generated across the air supply system due to the air pressure gradient established between the atmosphere and the air cavity. The air passage geometry and the pressure difference are the main parameters affecting the air flow-rate. The concrete surface confines the free flow jet downstream of the cavity, and powerful turbulent mixing takes place in the impact zone. Then, the entrained air becomes detrained successively. The air is transported away by the water in the vicinity of the chute. Therefore, a limited chute area is protected by each aerator [3].

Scholars have studied aerators both through prototype observations and in laboratory conditions [4]. Kramer and Hager [5] studied air bubble size distributions, air concentration, and flow velocity through experiments. They deduced that the velocity of bubble rise in chute flows is dependent on the Froude number. The effects of geometrical parameters on the streamwise distribution of air concentration downstream of aerators were analyzed by Pfister and Hager [6]. 
For many years, an important approach to study the aerated flow characteristics has been the use of physical models. In multiphase flow modeling, Computational Fluid Dynamics (CFD) has come into being as a major alternative. Beyond any doubt, the two methods complement each other. Using CFD, one can determine air-water flow fields for the aerated flow in detail to realize the impacts of the governing parameters [5]. Aerator flows operate at high velocities causing a challenge in numerical predictions. The velocity of flow may increase to as high as $30-45 \mathrm{~m} / \mathrm{s}$ in accordance with the water head. The exchange between the water and air begins to intensify as the velocity of the flow tends to go up. This issue reflects the fact that phase interactions formulations become more complicated in aerator flows. This can be attributed to the lack of data on prototype measurement for numerical model verification and calibration [1]. The two-phase flow characteristics and air concentration distribution in the vicinity and downstream of the aerator is of paramount importance to understand the performance of the aerator to better design and the need for further aerators.

Some numerical simulations have been done on spillways and weirs using one turbulence model. These simulations can be found in Al Zubaidy and Alhashimi [7] with RNG $k-\varepsilon$ turbulence model, Chinnarasri et al. [8], with Realisable $k-\varepsilon$ turbulence model, Chakib [9] and Mu et al. [10] with Standard $k-\varepsilon$ model and Morales et al. [11] with Standard $k-\omega$ model. Simulations for comparisons of different turbulence models in spillways and weirs are in Tadayon and Ramamurthy [12] and Rahimzadeh et al. [13].

On stepped spillways, in particular, investigations have been conducted to determine an appropriate and optimum turbulence model. Four turbulence models were compared by Qian et al. [14] (SST $k-\varepsilon$ model, realizable $k-\varepsilon$ model, LES model, and V2- $f$ model) showing that the most efficient model to simulate flow over stepped spillways that entails rotation is the $k-\varepsilon$ model. Also, using the realizable $k-\varepsilon$ model, the pressure field was investigated. To simulate the four-step stepped spillways, Daneshfaraz et al. [15] utilized the standard $k-\omega$ turbulence, standard $k-\varepsilon$, and renormalization group $k-\varepsilon$ models. Using the RNG $k-$ eturbulence model, which was considered as the optimal model of turbulence, the pressure distribution was investigated by comparison of the numerical and the physical values of water level. Other investigations for comparisons of turbulence models on stepped spillways have been conducted by Cheng et al. [16] and Kositgittiwong et al. [17].
In [16], the complex flow of stepped spillway was simulated satisfactorily by the numerical model compared to the experiments such as velocity distribution, pressure profiles on the step surface and interaction between air bubbles entered and recirculation of cavity in the skimming flow regime. Also, successful performance of modeling five turbulence models was achieved on large-scale stepped spillways suggested by Kositgittiwong et al. [17]. The $k-\omega$ models was rather better in the lower region while realizable $k-\varepsilon$ model resulted in moderately better results in the upper part of the velocity profile.

In smooth spillways with aerator, Yang et al. [1] and Yang et al. [18] used RNG $k-\varepsilon$ turbulence for simulating two-phase air-water flow. Realisable $k-\varepsilon$ turbulence model for this purpose has been used by Jothiprakash et al. [19] and Teng and Yang [4]. Standard $k-\varepsilon$ model has also been used for validation of the numerical model with aerator by Ozturk and Aydin [20]. However, there is no certain turbulence model to be used in CFD to determine the characteristics of air-water flow over aerators. The cavity length considered as one of the most important factors for spillway aeration along with the air concentration downstream of the aerator should be determined.

In the present study, the flow characteristics, air cavity length, and air concentration downstream of the aerator were investigated along the Gavoshan smooth spillway as a case study using numerical simulations with five different turbulence models. There is a need to access the best model regarding turbulence. To achieve this target, the cavity length should be assessed. The results of this research can be beneficial to distinguish the proper turbulence model to study and design such a device.

\section{Cavity length}

The length of the air cavity formed immediately downstream of the aerator's ramp is among the major factors that affects directly the discharge of air entrainment. It is complicated to calculate the cavity length $L$ since it is affected by several factors, such as hydraulic and structural parameters [21]. Fig. 1 is a schematic image of an air cavity formed downstream of an aerator ramp. In this figure, $\alpha$ is the chute angle to the horizontal plane; $\theta$ is the ramp angle related to the upstream bottom plane; $\theta^{\prime}$ is the emergence angle; $t_{r}$ is the ramp height; $t_{s}$ is the step height; $V_{0}$ is the mean velocity; $h$ is the flow depth normal to the bottom; $P_{a}$ is the pressure of the free surface and $P_{c}$ is the internal pressure of the air cavity. Therefore, $\Delta P=P_{a}-P_{c}$. 


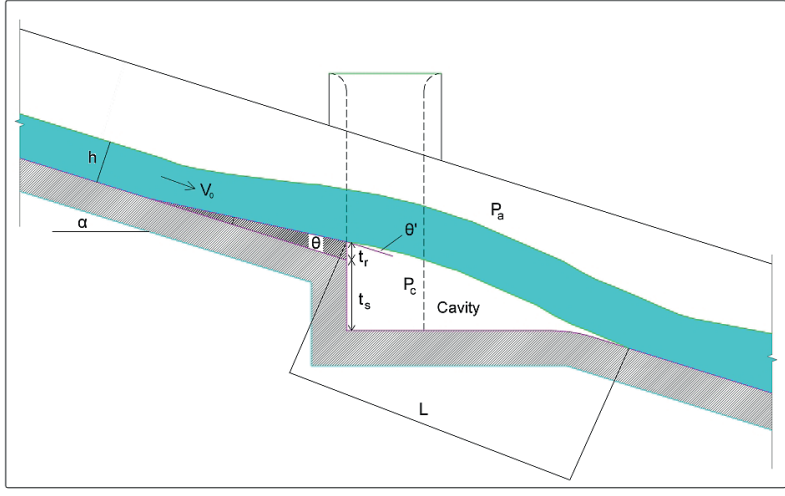

Fig. 1 Sketch of the flow over an aerator

A comparison between the five models of turbulence and experimental results was made for calculating cavity length to determine the optimum model for achieving air concentration distribution downstream of the aerator. Based on these results, another comparison was made among the five methods of calculating the cavity length (listed in Table 1) $[22,23]$, numerical results and experimental model results to obtain information about the efficiency of these methods.

\section{Physical model}

Based on the Water Research Institute hydraulic model report [24], the rock-fill dam of Gavoshan (height of $116 \mathrm{~m}$ from the river bed) and its related structures were constructed in 2004 at a distance of 75 kilometers from Kermanshah, Iran. The width and length of the dam crest are 14 and 615 meters, respectively. The spillway is an ogee weir situated on the right abutment. The spillway crest is 50 meters long through which the flow is entered into a 251 meters long chute including an aeration device. The distance between the spillway crest and the aeration device is 190 meters, and the spillway bed has an aerator

Table 1 Equations for estimating the cavity length

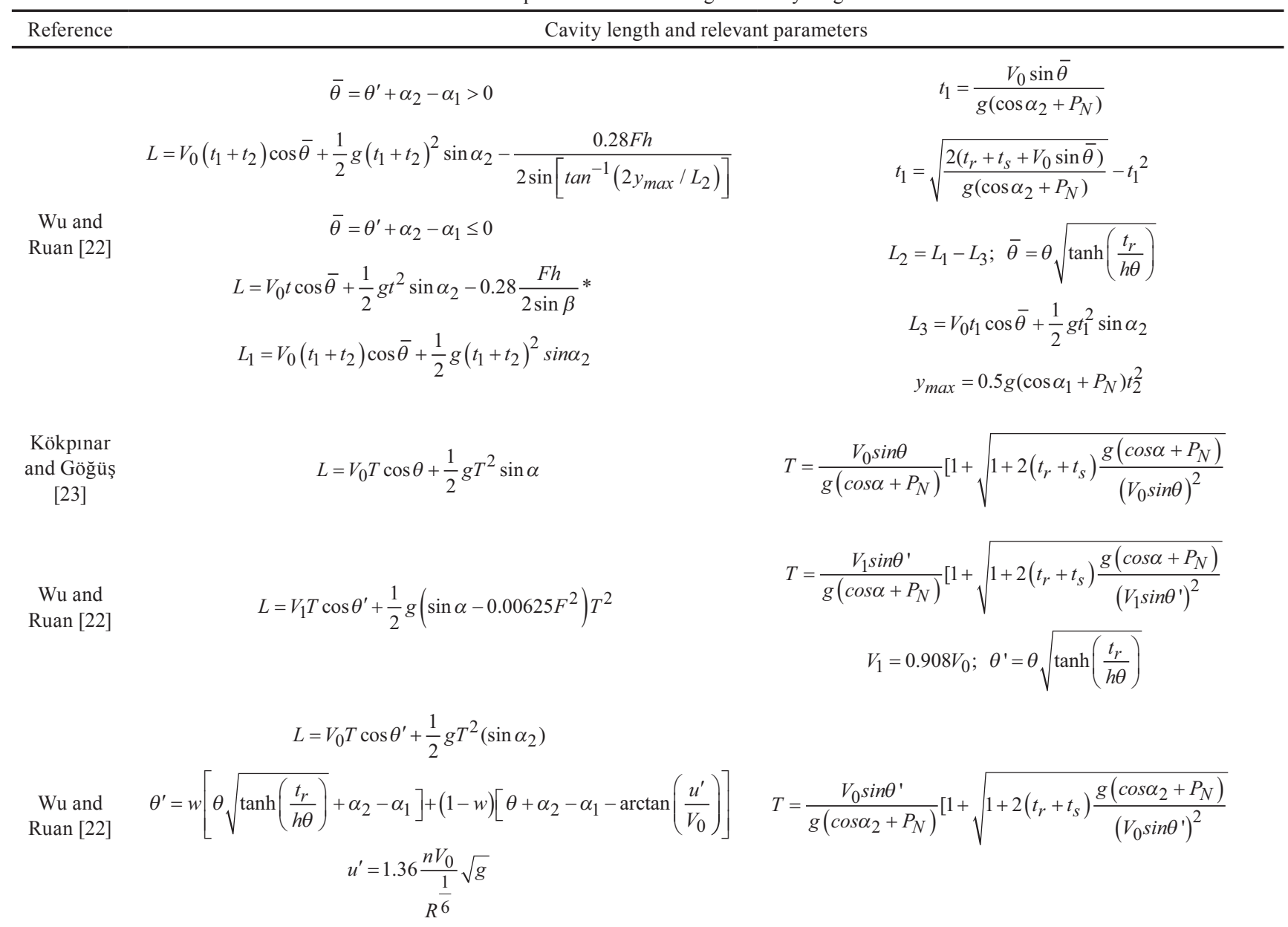

$\alpha_{1}$ and $\alpha_{2}$ are chute slopes, $V_{0}$ is mean velocity, $g$ is gravitational acceleration, $F$ is Froude number, $h$ is flow depth, $w$ is weight coefficients of $h$ and $u^{\prime}$, optimum value is 0.48 and $u^{\prime}$ is the maximum component of the spectrum of the transverse fluctuating velocity on the lower surface of the nappe [22], $P_{N}=\Delta p / \rho g h$ is the negative pressure index, $n$ is the Manning roughness coefficient, $t$ and $R$ is the hydraulic radius. Other parameters are determined by the relevant practical formulas defined into the table.

* this is not used in Gavoshan spillway 
ramp with an angle of $5^{\circ}$. From the spillway crest, the chute converges toward the downstream. At the aerator location, the chute is 36 meters wide (B), demonstrating that the aerator is also 36 meters wide. The air is supplied by an air shaft placed on both sides of the chute. The air shafts' centerlines are 40.20 meters apart. This shaft has a rectangular cross-section of $4.84 \mathrm{~m}^{2}$ area. The longitudinal profile of the aerator device and the detailed information of its plan are represented in Fig. 2. The physical model was constructed in $1 / 40$ scale.

The flow parameters such as the static pressure on the approach channel of the reservoir and spillway floor, the mean velocity, and flow depth were measured in the hydraulic model for the five flow rates at 15 cross-sections (represented by A-O). Table 2 represents the locations and elevations of these sections from the spillway to downstream.

In two-phase air-water flows, one can apprehend the contribution of scale in terms of the surface tension that cannot be completely resolved, when the Froude law is used for simulating the laboratory model. To prevent scale effects in two-phase air-water flows in Froude analogy conditions, Kobus [25] took into account the limitation of $1 \times 10^{5}$ for the Reynolds number. The Reynolds and Weber numbers recommended by Boes [26] to be $1 \times 10^{5}$ and 100 , respectively to minimize the scale effects. Pfister and Hager [6] deduced that the $W e>500$ constraint may cause slight scale effects. Therefore, the experimental model met the $R e>1 \times 10^{5}$ and $W e>500$ requirements. Also, to avoid the impact of surface tension, the minimum water depths of $2 \mathrm{~cm}$ and $5 \mathrm{~cm}$ were assumed on the chute and crest of the spillway physical model, respectively. Thus, the maximum flow rate criterion of the model was satisfied for the major parts [24].

\section{Numerical model}

Numerical simulations were carried out at the physical model dimensions by Fluent software version 6.3 using the Finite Volume Method (FVM). To specify the boundary conditions and producing the flow grids, the gambit pre-processor [19] version 2.3.16 was chosen. For the computational cells, the optimal dimensions are determined (within

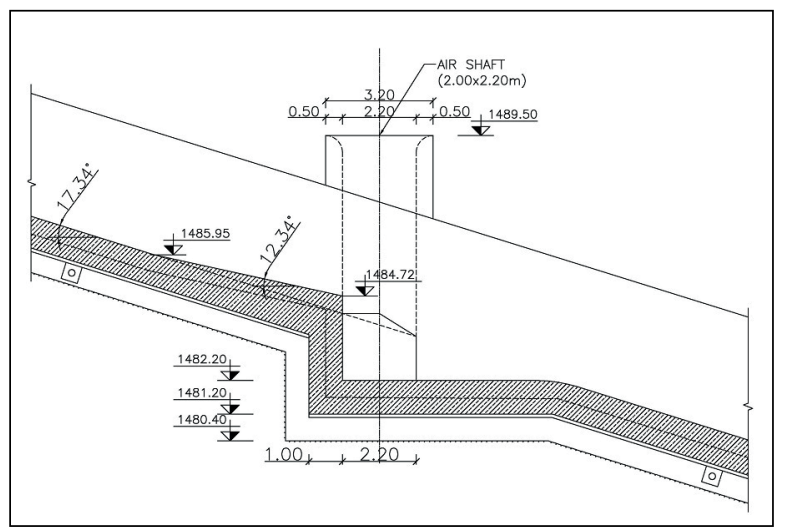

(a)

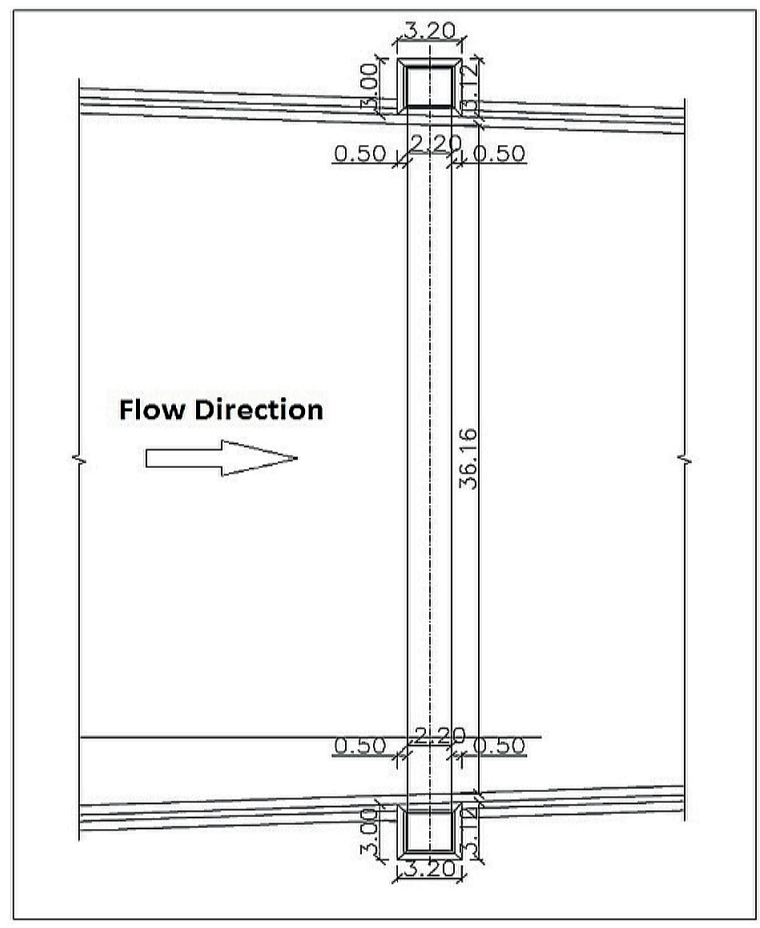

(b)

Fig. 2 a) Longitudinal profile and b) horizontal plan of Gavoshan aerator device

Table 2 Location and elevation of sections used for flow measurement on the spillway hydraulic model

\begin{tabular}{|c|c|c|c|c|c|}
\hline Section & $\begin{array}{l}\text { Horizontal distance from } \\
\text { spillway crest }(\mathrm{m})\end{array}$ & Section level (m) & Section & $\begin{array}{l}\text { Horizontal distance from } \\
\text { spillway crest }(\mathrm{m})\end{array}$ & Section level (m) \\
\hline $\mathrm{D}$ & 0 & 1545.5 & $\mathrm{~J}$ & 181 & 1487 \\
\hline $\mathrm{E}$ & 14.5 & 1539 & K & 200.2 & 1481 \\
\hline $\mathrm{F}$ & 46.5 & 1529 & $\mathrm{~L}$ & 222.7 & 1474 \\
\hline G & 78.5 & 1519 & M & 255.1 & 1464.07 \\
\hline $\mathrm{H}$ & 110.6 & 1509 & $\mathrm{~N}$ & 266 & 1461.63 \\
\hline I & 142.6 & 1499 & $\mathrm{O}$ & 274.9 & 1463.53 \\
\hline
\end{tabular}


the $0.005-0.025 \mathrm{~m}$ range). In the high-gradient parts and especially for the aeration zone, the size of the numerical cells is reduced, so that the air concentration and hydraulic characteristics of the aerator cavity are calculated precisely. To reduce the time required for simulation and obtain more detailed data of the aeration zone, the considered numerical flow domain was from section $E$ to the end of the flip bucket. The flow field is assumed to be symmetrical so that only half-width of the chute was simulated. Fig. 3 depicts the boundary conditions.

\subsection{Volume of Fluid model (VOF)}

The volume of fluid (VOF) was utilized for the air-water interface tracking as suggested by Hirt and Nichols [27]. The sum of the volumetric fractions of water, $\alpha_{\omega}$, and air, $\alpha_{a}$, equals one in each computational cell and can be presented as

$\alpha_{\omega}+\alpha_{a}=1 ; 0 \leq \alpha_{\omega}, \alpha_{a} \leq 1$.

The tracking interface between water and air in this approach was determined by solving the continuity equation for the water volume fraction:

$\frac{\partial \alpha_{\omega}}{\partial t}+\frac{\partial \alpha_{\omega} u_{i}}{\partial x_{i}}=0$.

\subsection{Reynolds-Averaged Navier-Stokes equations}

The governing equations applied for the numerical model in order to determine the flow field are conservation of mass and momentum. The mass conservation equation for the universal case of compressible and incompressible flows is: $\frac{\partial \rho}{\partial t}+\frac{\partial}{\partial x_{i}}\left(\rho u_{i}\right)=0$.

And the momentum equation is:

$$
\begin{aligned}
& \frac{\partial \rho u_{i}}{\partial t}+\frac{\partial}{\partial x_{i}}\left(\rho u_{i} u_{j}\right)= \\
& -\frac{\partial p}{\partial x_{i}}+\rho g_{i}+\frac{\partial}{\partial x_{i}}\left[\left(\mu+\mu_{t}\right)\left(\frac{\partial u_{i}}{\partial x_{j}}+\frac{\partial u_{j}}{\partial x_{i}}\right)\right],
\end{aligned}
$$

where $u_{i}$ is speed agent in $x_{i}$ direction, $u_{j}$ is speed agent in $x_{j}$ direction, $p$ is total pressure, $\rho$ is fluid density, $g$ is acceleration of gravity, $\mu$ is turbulent viscosity and $t$ is time [9].

\subsection{Turbulence models}

\subsubsection{Standard $k-\varepsilon$ model for the VOF flow}

The standard (ST) model of $k-\varepsilon$ turbulence suggested by Launder and Spalding [28] was practical in flow calculations of applied engineering, presenting economic benefits and reasonable precision. The following equations are the ones to determine the turbulent kinetic energy, $k$, and its dissipation rate, $\varepsilon$ :

$$
\begin{aligned}
& \frac{\partial(\rho k)}{\partial t}+\frac{\partial}{\partial x_{i}}\left(\rho k u_{i}\right)= \\
& \frac{\partial}{\partial x_{j}}\left[\left(\mu+\frac{\mu_{t}}{\sigma_{k}}\right) \frac{\partial k}{\partial x_{j}}\right]+G_{k}+G_{b}-\rho \epsilon-Y_{M}+S_{k}
\end{aligned}
$$

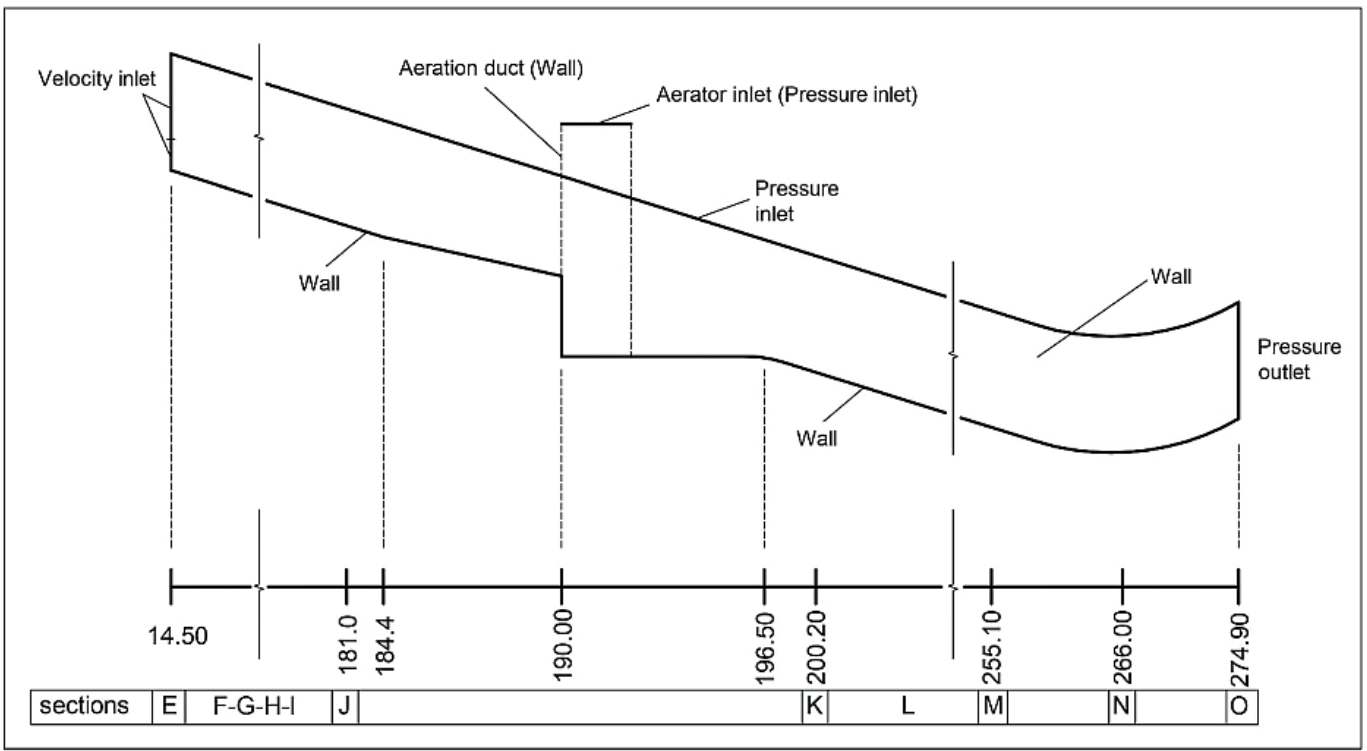

Fig. 3 Boundary conditions defined in numerical simulation 
$\frac{\partial(\rho \epsilon)}{\partial t}+\frac{\partial}{\partial x_{i}}\left(\rho \epsilon u_{i}\right)=$ $\frac{\partial}{\partial x_{j}}\left[\left(\mu+\frac{\mu_{t}}{\sigma_{\epsilon}}\right) \frac{\partial k}{\partial x_{j}}\right]+C_{1 \epsilon} \frac{\epsilon}{k}\left(G_{k}+C_{3 \epsilon} G_{b}\right)-C_{2 \epsilon} \rho \frac{\epsilon^{2}}{k}+S_{\epsilon}$,

where $G_{b}, G_{k}$ are the turbulence kinetic energy generation due to the buoyancy and mean velocity gradients, respectively; the contribution of the fluctuating dilatation in compressible turbulence to the total dissipation rate is shown by $Y_{M}$, the mean component of velocity in the $i$-th direction is represented by $u_{I}$; the turbulent viscosity is represented by $\mu_{t}$, and calculated by $\mu_{t}=\rho C_{\mu}\left(k^{2} / \epsilon\right)$; model constants are $C_{\mu}, C_{1 \epsilon}, C_{2 \epsilon}, \sigma_{k}$, and $\sigma_{\epsilon}$ that are determined as follows:, $C_{\mu}=0.09, C_{1 \epsilon}=1.44, C_{2 \epsilon}=1.92$, and $\sigma_{k}=1.0$, and $\sigma_{\epsilon}=1.3 . S_{\epsilon}$ are $S_{k}$ source terms defined by the user. These terms are calculated empirically by formulas for $k-\varepsilon$ and $k-\omega$ turbulence models based on the following parameters: Reynolds number, turbulence length scale, hydraulic diameter and mean flow velocity. This model is a semi-empirical on the basis of transport equations for turbulence kinetic energy dissipation rate and turbulence kinetic energy. This model is only valid for fully turbulent flows according to the assumption.

\subsubsection{RNG $k-\varepsilon$ model for the VOF flow}

Yakhot and Orszag [29] presented the model of RNG (renormalization group) $k-\varepsilon$ turbulence. The equations for turbulent kinetic energy, $k$, and its dissipation rate, $\varepsilon$ are as follows:

$$
\begin{aligned}
& \frac{\partial(\rho k)}{\partial t}+\frac{\partial}{\partial x_{i}}\left(\rho u_{i} k\right)= \\
& \frac{\partial}{\partial x_{j}}\left[\left(\alpha_{k} \mu_{e f f} \frac{\partial k}{\partial x_{j}}\right)\right]+G_{k}+G_{b}-\rho \epsilon-Y_{M}+S_{k}, \\
& \frac{\partial(\rho \epsilon)}{\partial t}+\frac{\partial}{\partial x_{i}}\left(\rho u_{i} \epsilon\right)=\frac{\partial}{\partial x_{j}}\left[\alpha_{\epsilon} \mu_{e f f} \frac{\partial \epsilon}{\partial x_{j}}\right] \\
& +C_{1 \epsilon} \frac{\epsilon}{k}\left(G_{k}+C_{3 \epsilon} G_{b}\right)-C_{2 \epsilon} \rho \frac{\epsilon^{2}}{k}-R_{\epsilon}+S_{\epsilon},
\end{aligned}
$$

where the inverse effective Prandtl numbers are presented by $\alpha_{k}, \alpha_{\epsilon} ; C_{1 \epsilon}=1.42, C_{2 \epsilon}=1.68$ are the constants of the model; $\quad R_{\epsilon}=C_{\mu} \rho \eta^{3}\left(1-\eta / \eta_{0}\right) \epsilon^{2} /\left(k\left(1+\beta \eta^{3}\right)\right)$, where $\eta=4.38, \beta=0.12$, and $\eta \equiv S k / \epsilon$. This model was obtained by using a rigorous statistical approach. Although in terms of formulas, it is similar to the model of ST $k-\varepsilon$ turbulence, some refinements are required: (1) to improve the accuracy of rapidly strained flows, an additional term should be added to the equation of turbulence kinetic energy dissipation rate; (2) in order to improve the accuracy for swirling flows, one should include the swirl effect; (3) analytical formula are used to determine the Prandtl numbers.

\subsubsection{Realizable $k-\varepsilon$ model for the VOF flow}

Shih et al. [30] presented a model for the realizable (Rl) $k-\varepsilon$ turbulence model. Below equations are presented to determine the turbulent kinetic energy, $k$, and its dissipation rate, $\varepsilon$ :

$\frac{\partial(\rho k)}{\partial t}+\frac{\partial}{\partial x_{j}}\left(\rho u_{i} k\right)=$
$\frac{\partial}{\partial x_{j}}\left[\left(\mu+\frac{\mu_{t}}{\sigma_{k}}\right) \frac{\partial k}{\partial x_{j}}\right]+G_{k}+G_{b}-\rho \epsilon-Y_{M}+S_{k}$,

$$
\begin{aligned}
& \frac{\partial(\rho \epsilon)}{\partial t}+\frac{\partial}{\partial x_{j}}\left(\rho u_{i} \epsilon\right)=\frac{\partial}{\partial x_{j}}\left[\left(\mu+\frac{\mu_{t}}{\sigma_{\epsilon}}\right) \frac{\partial \epsilon}{\partial x_{j}}\right] \\
& +\rho C_{1} S_{\epsilon}-\rho C_{2} \frac{\epsilon^{2}}{k+\sqrt{v \epsilon}}+C_{1 \epsilon} \frac{\epsilon}{k} C_{3 \epsilon} G_{b}+S_{\epsilon},
\end{aligned}
$$

where $v$ represents the turbulent kinematic viscosity; $C_{1}=\max \left[0.43, \eta /(\eta+5)\right.$ and $\eta=S K / \epsilon, S=\sqrt{2 S_{i j} S_{i j}}$, where $S_{i j}=0.5\left(\partial u_{j} / \partial x_{i}+\partial x_{i} / \partial x_{j}\right)$; and the empirical constants are: $C_{2}=1.9, C_{1 \epsilon}=1.44, \sigma_{\epsilon}=1.2$, and $\sigma_{k}=1.0$. Through the same model, one can precisely simulate the spreading rate of both round and planar jets and the flows involving rotation, boundary layers subject to powerful adverse pressure gradients, recirculation, and separation.

\subsubsection{Standard $\boldsymbol{k}$ - $\omega$ model for the VOF flow}

Wilcox [31] presented a model for standard (ST) $k-\omega$ turbulence that includes some modifications for low-Reynoldsnumber effects, shear flow spreading, and compressibility. The following equations are the ones to determine the turbulent kinetic energy, $k$, and its dissipation rate, $\omega$ :

$$
\begin{aligned}
& \frac{\partial(\rho k)}{\partial t}+\frac{\partial}{\partial x_{i}}\left(\rho u_{i} k\right)=\frac{\partial}{\partial x_{j}}\left[\Gamma_{k} \frac{\partial k}{\partial x_{j}}\right]+G_{k}-Y_{k}+S_{k}, \\
& \frac{\partial(\rho \omega)}{\partial t}+\frac{\partial}{\partial x_{i}}\left(\rho u_{i} \omega\right)=\frac{\partial}{\partial x_{j}}\left[\Gamma_{\omega} \frac{\partial \omega}{\partial x_{j}}\right]+G_{\omega}-Y_{\omega}+S_{\omega},
\end{aligned}
$$

Where, $\Gamma_{\omega}$ and $\Gamma_{k}$ are the effective diffusivity of $\omega$ and $k$, respectively; $G_{\omega}$ is the generation of $\omega ; S_{\omega}$ is the source term defined by the user, and $Y_{\omega}$ and $Y_{k}$ are the 
dissipation of $\omega$ and $k$, respectively. This is an empirical model designed based on equations of model transport for the turbulence kinetic energy and its dissipation rate.

\subsubsection{SST $\boldsymbol{k}$ - $\omega$ model for the VOF flow}

Menter [32] developed a model for the shear-stress transport (SST) $k-\omega$ turbulence. The equations for the turbulent kinetic energy, $k$, and its dissipation rate, $\omega$ are as follows:

$$
\begin{aligned}
& \frac{\partial(\rho k)}{\partial t}+\frac{\partial}{\partial x_{i}}\left(\rho u_{i} k\right)=\frac{\partial}{\partial x_{j}}\left[\Gamma_{k} \frac{\partial k}{\partial x_{j}}\right]+G_{k}-Y_{k}+S_{k}, \\
& \frac{\partial(\rho \omega)}{\partial t}+\frac{\partial}{\partial x_{i}}\left(\rho u_{i} \omega\right)=\frac{\partial}{\partial x_{j}}\left[\Gamma_{\omega} \frac{\partial \omega}{\partial x_{j}}\right]+G_{\omega}-Y_{\omega}+D_{\omega}+S_{\omega},
\end{aligned}
$$

where, $\mathrm{D}_{\omega}$ is the term representing the cross-diffusion.

\subsection{Grid convergence}

During convergence estimations, grid convergence and iterative convergence should be realized for time-dependent simulations. For iterative convergence, and for every equation, one should achieve three orders of decrement for the magnitude of the normalized residuals. Fine grid spacing and incremental initial time-step are the prerequisites to develop a model with unsteady, free-surface nature [33]. The solution convergence and profiles of water free surface were controlled uninterruptedly during the whole calculations. The convergence criterion was satisfied when the normalized residual was of an order of $1 \times 10^{-3}$ for every variable $[34,35]$. After the numerical solution convergence was satisfied, the grid refinement was conducted in conformity with the magnitude of flow velocity, so that more accurate results were achieved; thereby, the model was applied. To create the mesh for the same numerical model, one can use different grid sizes. Initially, a mesh of coarse nature was generated. Thereafter, to generate finer grids, it undergoes refinement twice. For determining the Grid Convergence Indices, three sets of coarse grid (0.0066-0.0165), medium grid (0.006-0.015), and fine grid (0.0054-0.0135) were used. Mesh was unstructured and consisted of different types of hexahedral, tetrahedral/hybrid and hexahedral/wedge mesh. Richardson Extrapolation was also utilized to evaluate the errors in discretization. The GCI (Grid Convergence Index) technique introduced by Richardson Extrapolation was considered as well. Changes in cell size recognized as refinement factors are assumed to be 1.11 by referring to Roache suggestion [36] in the 1994 by using lower values of $10 \%$ difference for the same factor [37]. Also, for a computer of the same processing power, the time spent per iteration for the finer grid is longer than that of the medium-sized one. The evaluations showed that a mesh with 940000 cells can be dense enough to model the aerator flows.

The wall function approach was used for $k-\varepsilon$ models since this approach significantly saves the resources of computations because the regions near the wall, where the variables of the solution can change rapidly, does not need to be resolved. For $k-\omega$ model, fine mesh used near the wall. $\mathrm{y}^{+}$value used for all of the turbulence models. The range of the $\mathrm{y}+$ for the turbulence models with wall functions is $30<\mathrm{y}^{+}<300$ and for other models equals 1. [34]

\section{Results and discussions}

The risk of potential cavitation on the chute spillways without an aeration device was investigated by Shayanseresht [38]. It was argued that the surface of the spillway at a distance of 180-225 $\mathrm{m}$ from the spillway crest is subjected to damages due to lower cavitation indices compared to the critical value of 0.2 . The obtained results of the same study led to numerical simulation for the Gavoshan spillway that was equipped with an aerator instrument on the chute bed. Air concentration distribution in the vicinity and downstream of the aerator was calculated by Shayanseresht and Manafpour [39].

The flow depth in the longitudinal profiles for different turbulence models after converting the results to the prototype dimensions is illustrated in Fig. 4. The flow depth decreases up to the aerator device location in the longitudinal profile as the velocity increases in a constant flow rate for all the models. The mixing air and water phases at the aerator result in flow depth increment in this area along with higher values on the flip bucket as the velocity of flow decreases.

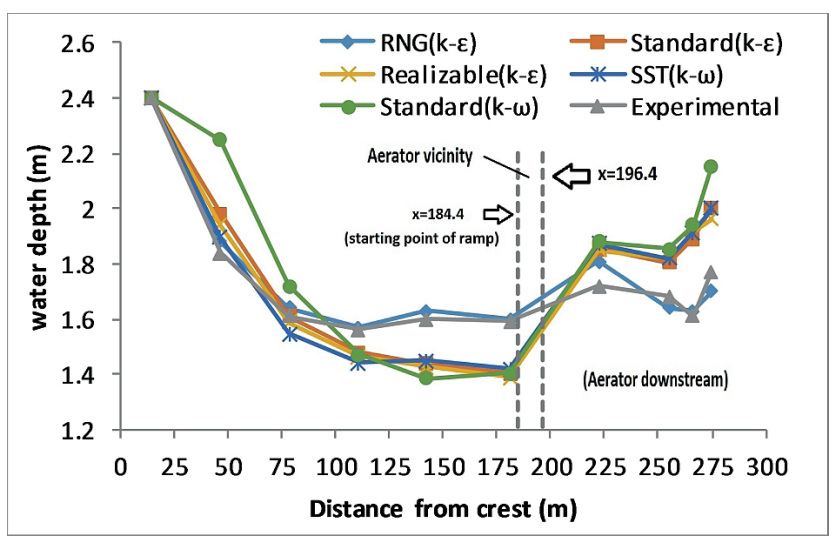

Fig. 4 Comparisons of flow depths at longitudinal profiles on centerline between experimental and numerical simulation for different turbulence models 
Fig. 5(a), illustrates the mean flow velocity for the different turbulence models. As the depth of flow is increased, its velocity is inclined to be decreased and vice versa. Flow velocity does not fluctuate substantially from the inlet to sections downstream towards the aerator. Thereafter, the velocity profiles are divided toward the flow output. The velocity is decreased due to the bottom inversion and flip bucket convexity.

Pathlines for the mixture of air-water flow are shown in Fig. 5(b) for the RNG $k-\varepsilon$ turbulence model. The values shown are in the hydraulic model. The eddies (recirculation flow of air phase) formed in a clockwise direction and the center of each eddy is near and above the horizontal surface of the step. Velocity magnitude increases from the center of eddies to the free surface of the flow. It is formed near the primary water flow above the aerator. Thus, the water flow is the reason to set up the cavity-recirculating flow to drag the air into the cavity.

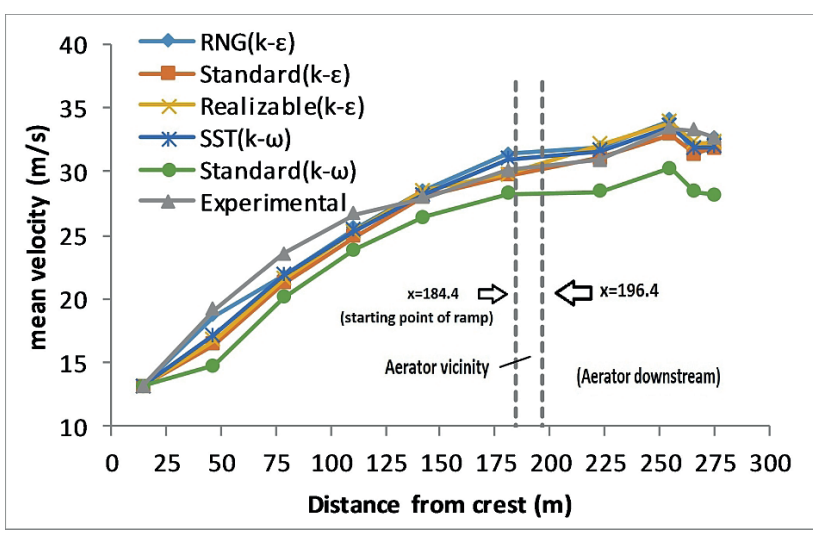

(a)

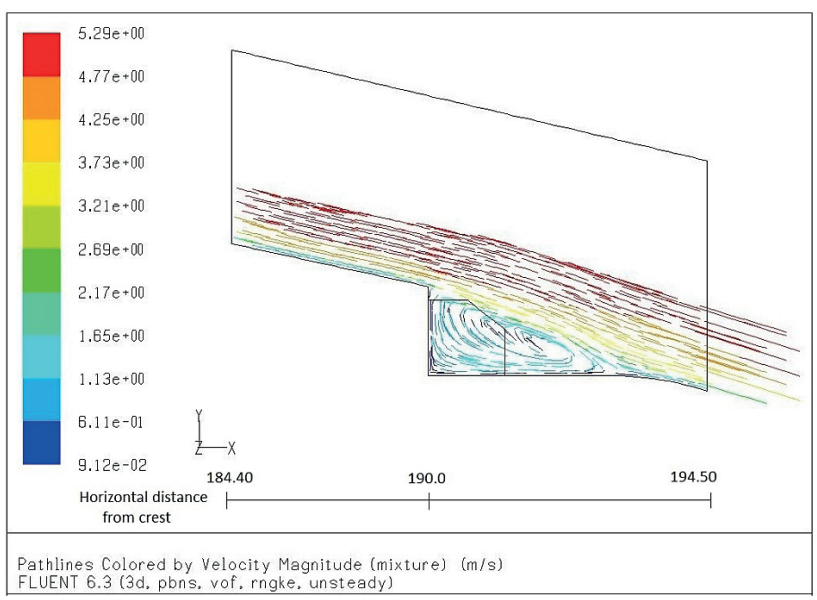

(b)

Fig. 5 a) Comparisons of mean flow velocity between experimental and numerical simulation for different turbulence models, b) Pathlines in RNG k- $\varepsilon$ turbulence model
The bottom mean pressure heads along the spillway chute are depicted in Fig. 6. According to the data derived from Water Research Institute [24] the mean pressures of the bed (measured by piezometers) were not evaluated when the aeration system was added for the sections downstream of the aerator. Therefore, the values downstream of the spillway are related to the spillway lacking an installed aerator. The report also does not comment on the sudden pressure reduction in section I, leading to a high discrepancy compared to the numerical data. The aerator ramp has a distance of $190 \mathrm{~m}$ from the spillway crest. Due to the flow separation and the impinging jet action over the ramp, the bottom pressure fluctuations at the vicinity of the aerator ramp (184.4 $\mathrm{m}$ to $240 \mathrm{~m}$ away from the spillway crest) are evident [38]. Due to the reverse slope of the ramp, the bottom pressure is increased leading to increased shear stresses on the flow. The mean pressure distribution of flow is quickly changed in the impact region of the jet from a minimum pressure gradient on the top surface of the nappe to the maximum pressure gradient at the bottom. The flow gets into the concave curvature of the bucket and goes upwards. The pressure gained from the centrifugal force at the curvature causes higher bottom static pressure [39]. Fig. 7 shows that the pressure changes from hydrostatic pressure on the ramp to the sub-atmospheric pressure into the cavity.

Two approaches were taken into consideration to compare the performance of turbulence models statistically: 1. Error percentage bars (Fig. 8), and 2. The estimation of root mean square error (RMSE) criterion through

$R M S E=\sqrt{\frac{1}{n} \sum_{1}^{n}\left(\text { variable }_{\text {physical }}-\text { variable }_{\text {numerical }}\right)^{2}}$.

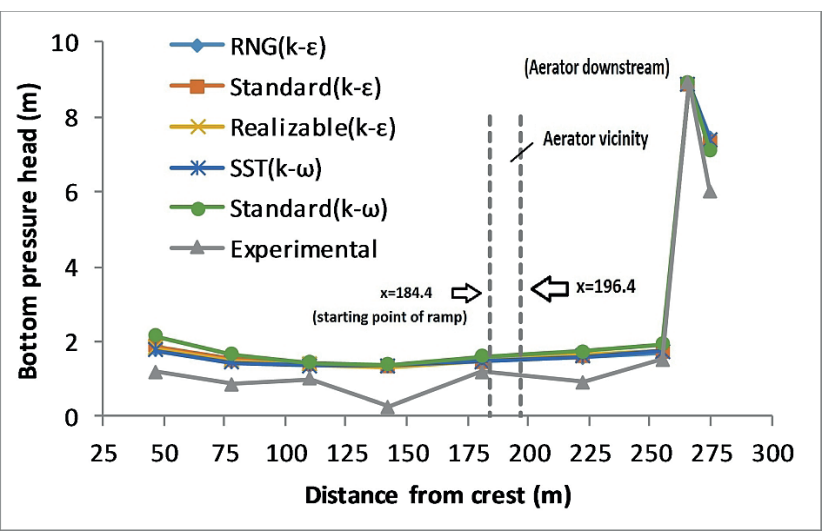

Fig. 6 Comparison of bottom mean pressure heads obtained from the numerical analysis using different turbulence models 


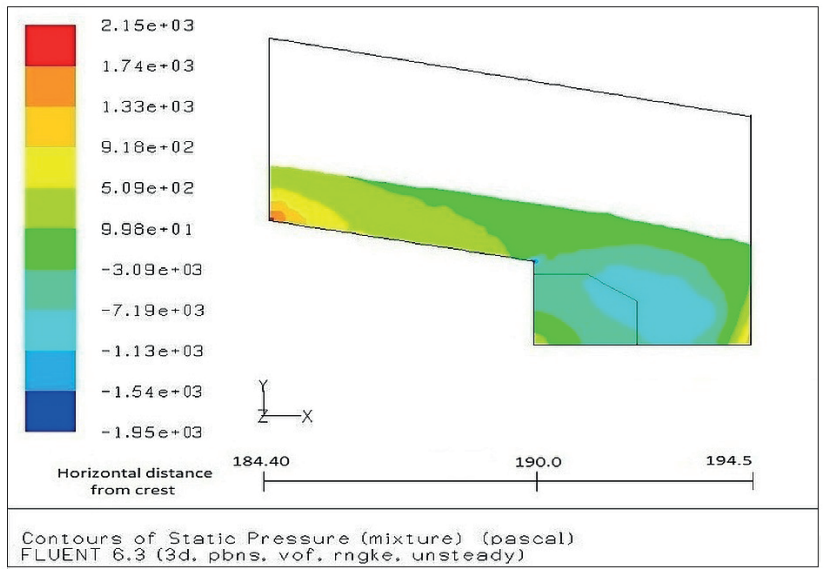

Fig. 7 Contours of static pressure in the vicinity of aerator in RNG $k-\varepsilon$ turbulence mode

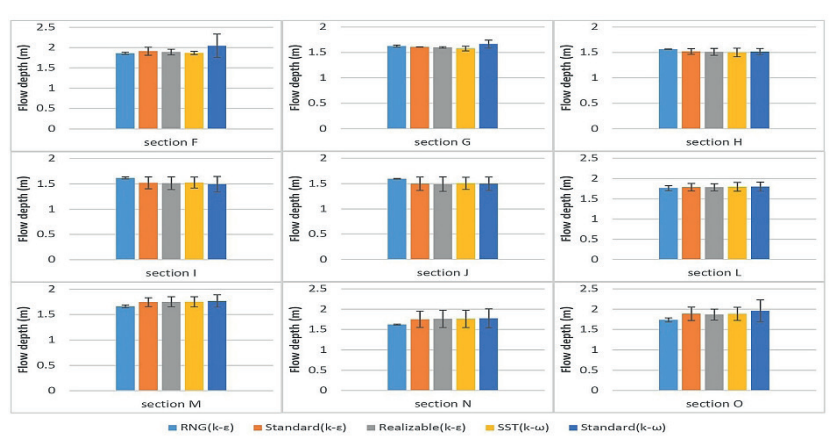

(a)

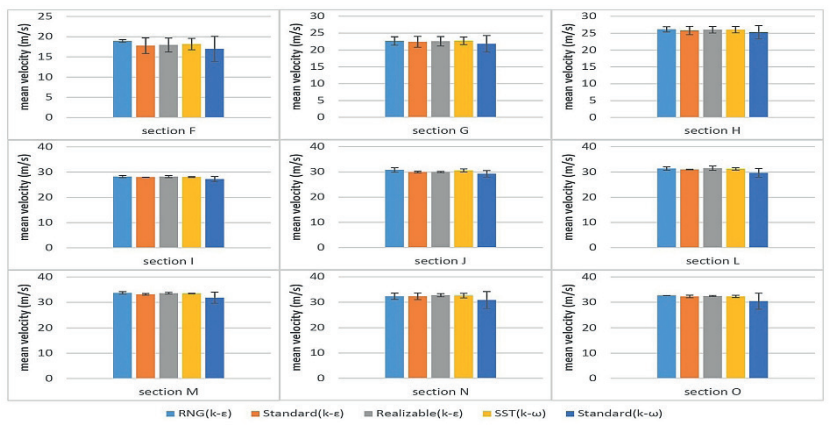

(b)

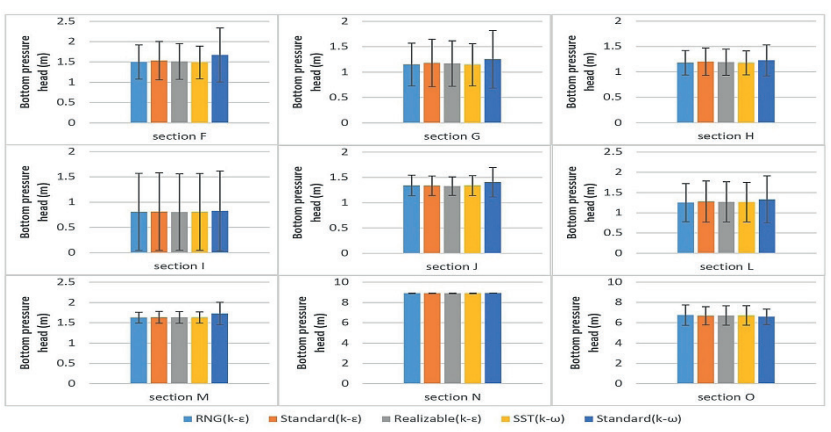

(c)

Fig. 8 Error bars for a) flow depth, b) mean velocity and c) bottom pressure head obtained from the numerical analysis for different turbulence models
Where, the number of measurement points for pressure in each profile is shown by $n$. The variable $_{\text {numerical }}$ and variable $_{\text {physical }}$ are the numerical and physical values of all parameters, respectively. Based on the root mean square error definition, the lower is the root mean square error, the more precise is the model.

It is seen in Fig. 4 that the most appropriate model to simulate the free surface of the flow is the RNG k- $\varepsilon$ turbulence model. The error bars for the flow depth has been illustrated in Fig. 8(a). The least and the biggest error percentage was related to the RNG $k-\varepsilon$ turbulence and Standard $k-\omega$ models, respectively. The maximum differences between numerical and experimental data for flow velocity were related to the Standard $k-\omega$ model shown in Fig. 8(b). The minimum value for error percentage, however, was for the RNG $k-\varepsilon$ turbulence model. The second least error value was set by the SST $k-\omega$ model. Except for the Standard $k-\omega$ model, the error percentage produced by different turbulence models for bed pressure head (Fig. 8(c)) had very slight differences. These values were higher than those of the flow depth and the velocity since the bottom pressure calculated from the physical model was obtained for the spillway chute without any installed aerator device.

The values of RMSE of the numerical results using five turbulence models are shown in Table 3. It is evident that (1) at each profile, all numerical models of turbulence present satisfactory results; (2) one can consider the model of RNG $k-\varepsilon$ turbulence as the preferable model for simulation of the velocity and depth of the flow. In return, St $k-\omega$ turbulence model indicated a larger error in the estimation of the bottom pressure compared to the other turbulence models as seen from Table 3 .

To specify the most efficient model for determining air concentration profiles downstream of the aerator, the length of the cavity (jet) formed downstream of the aerator ramp is calculated and compared with the physical model and some empirical formulas defined by researchers (Table 1). The volume fraction of the flow passing the aerator and the length of the air cavity formed downstream of the ramp are illustrated in Fig. 9 using the RNG

Table 3 The RMSE values of different turbulence models

\begin{tabular}{lccccc}
\hline Variable & $\begin{array}{c}\text { RNG } \\
k-\varepsilon\end{array}$ & $\begin{array}{c}\text { St } \\
k-\varepsilon\end{array}$ & $\begin{array}{c}\text { Rl } \\
k-\varepsilon\end{array}$ & $\begin{array}{c}\text { SST } \\
k-\omega\end{array}$ & $\begin{array}{c}\text { St } \\
k-\omega\end{array}$ \\
\hline Flow depth & 0.042 & 0.159 & 0.160 & 0.161 & 0.24 \\
Flow velocity & 1.049 & 1.42 & 1.21 & 1.09 & 3.20 \\
Bed pressure head & 2.79 & 2.80 & 2.78 & 2.80 & 3.05 \\
\hline
\end{tabular}




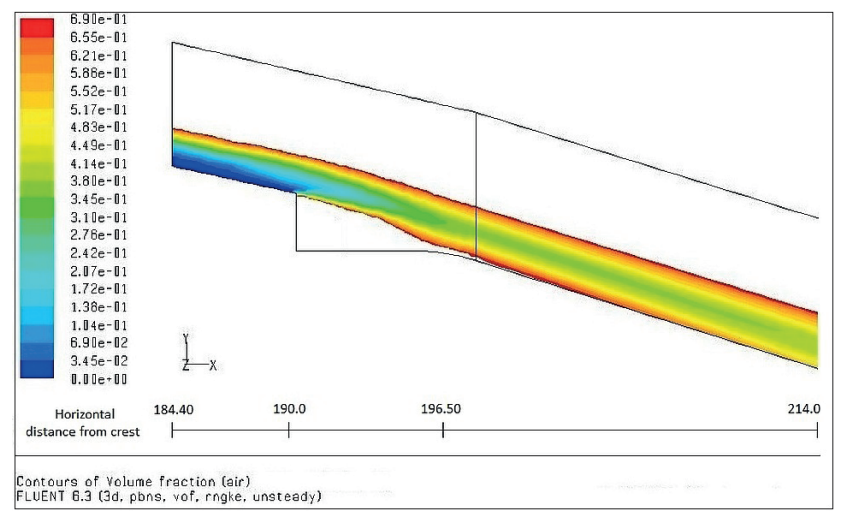

Fig. 9 Contours of air volume fraction of flow passing an aerator applying RNG $k-\varepsilon$ turbulence mode

$k-\varepsilon$ turbulence model. The core of the flow and its aeration are seen in this figure. Most of the aeration has taken place from the upper and lower nappe where the flow is in touch with the atmosphere and the cavity, respectively. Center layers (core) of the jet are mainly the water phase.

Fig. 10 indicates the length of the air cavity (distance from the separation point of the flow on the ramp to the impact point of the lower nappe) obtained from the numerical analyses using various turbulence models and the physical model as well. As seen from Fig. 10, the most accurate turbulence model to estimate the cavity length is the RNG $k-\varepsilon$ model which shows a very slight difference with the experimental results. Other turbulence models' results are in a very close interval compared with one another comprised of an error percentage of $1 \%$ difference, except for the Standard $k-\omega$ model with an $8 \%$ difference with the SST $k-\omega$ mode. In this case, RNG $k-\varepsilon$ is the most efficient model for calculating the air cavity length by considering time cost and the obtained results.

A comparison is made in Fig. 11 among the cavity length found numerically using RNG $k-\varepsilon$ model, experimentally and empirically using four different equations presented in Table 1. One can conclude that the length of the cavity is closely associated with the flow emergence angle $\theta^{\prime}$ over the aerators [21]. The flow impact angle to the bottom is strongly affected by the same angle. Thus, the flow emergence angle over aerators should be determined. This angle is dominated by the overall effects of many factors of the hydraulic and structural parameters. The most important parameter affecting this angle is the flow depth considered in the first, third, and fourth equations [22] in Table 1.

The vertical distribution of air concentration is shown in Fig. 12 at different sections downstream of the aerator ramp, where $t_{r}$ and $x$ are the ramp height $\left(t_{r}=0.5 \mathrm{~m}\right)$

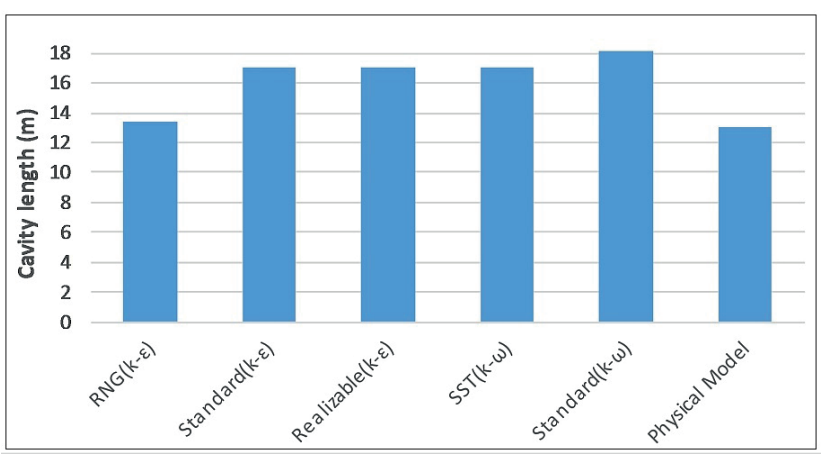

Fig. 10 Cavity length obtained from the numerical analysis using different turbulence models and the physical model

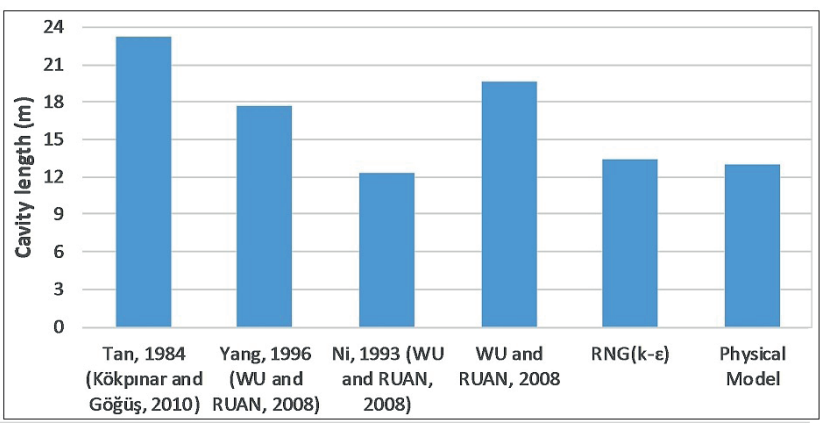

Fig. 11 Cavity length estimated by using empirical equations, RNG $k-\varepsilon$ model and physical model

and the distance from the ramp end, respectively. It can be seen that across the jet, towards its core, the air concentration is decreased. Furthermore, downstream of the cavity, air concentration is increased from the spillway bottom toward the water surface where air bubbles leave the flow. Also, as the fluid moves downstream, the air concentration of flow reduces gradually and reaches a uniform state. However, the concentration of air on the spillway bottom is greatly increased compared to its value upstream of the aerator ramp. Also, the air concentration is reduced significantly at the jet core, when the flow rate of the spillway, and thereby, the thickness of the jet is increased.

Air concentration distribution estimated by application of various turbulence models has a very slight discrepancy in the $y$-direction, moving from bottom to surface of the flow. The differences are seen mainly in the bottom of the chute for the RNG $k-\varepsilon$ model and the Standard $k-\omega$ model in $x / t_{r}=5.60,10.20$, and 121.80 . Thus, it is necessary to achieve bottom air concentration profiles as the most prominent factor for making the flow more compressible to mitigate cavitation damage. Fig. 13 shows the chute bottom air concentration along the flow direction for different turbulence models. Except for the RNG $k-\varepsilon$ model, other models demonstrate almost the same values 


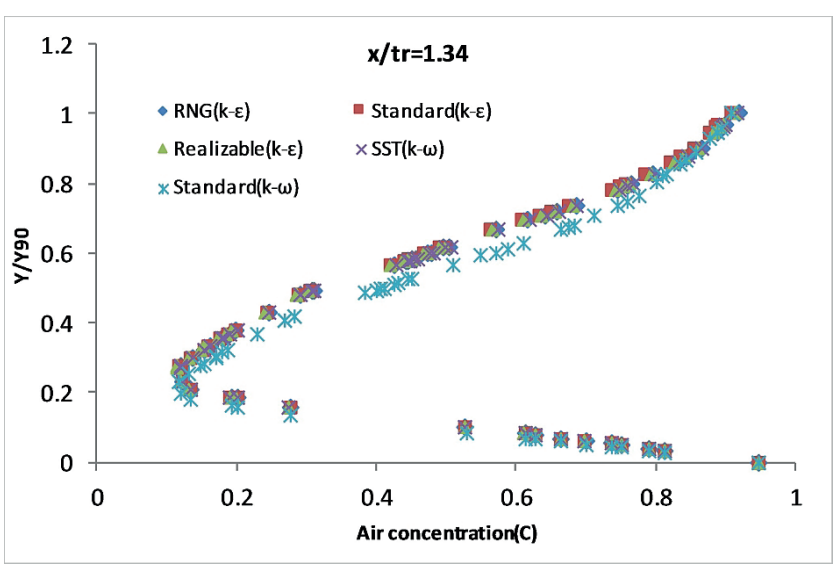

(a)

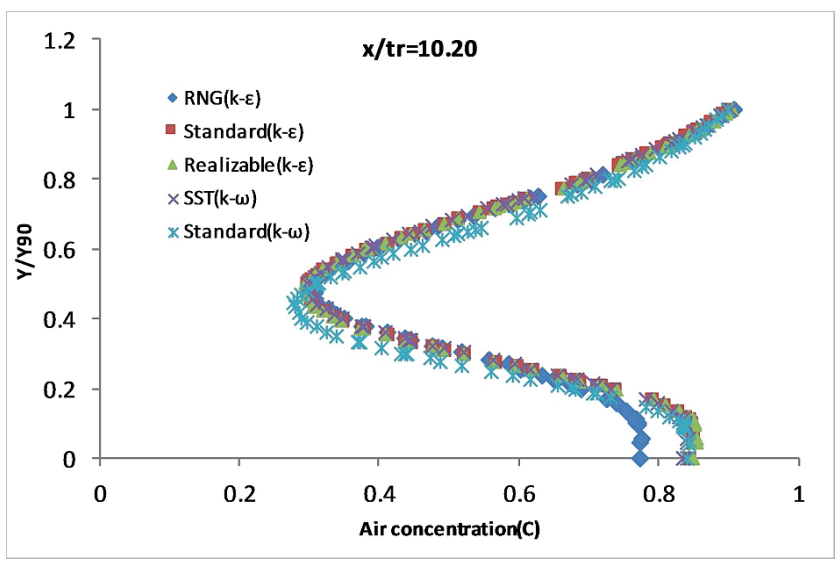

(c)

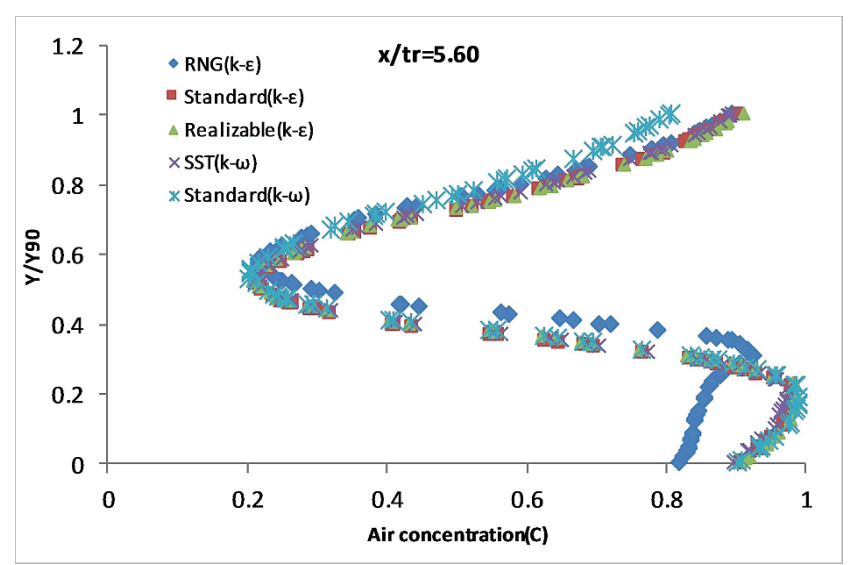

(b)

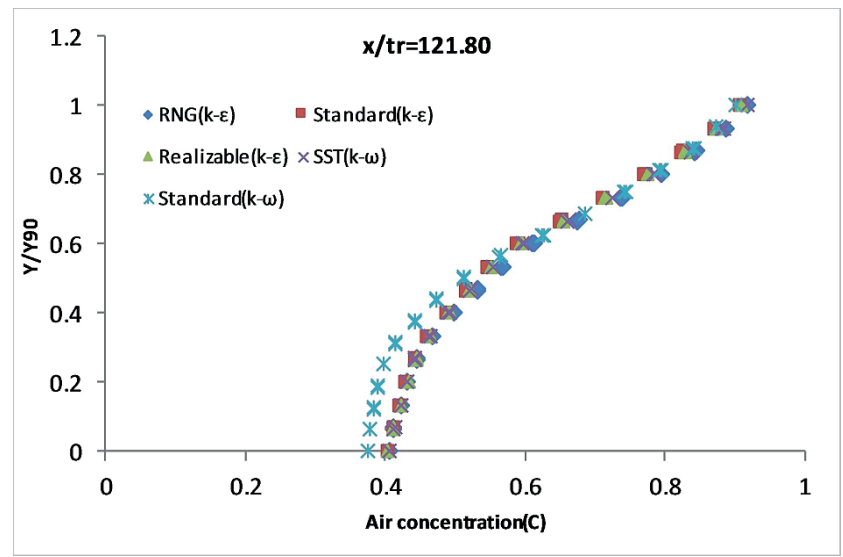

(d)

Fig. 12 Comparisons of air concentration distribution obtained by using the different turbulence models, a) $x / t_{r}=1.34$, b) $x / t_{r}=5.60$, c) $x / t_{r}=10.20$, d) $x / t_{r}=121.8$

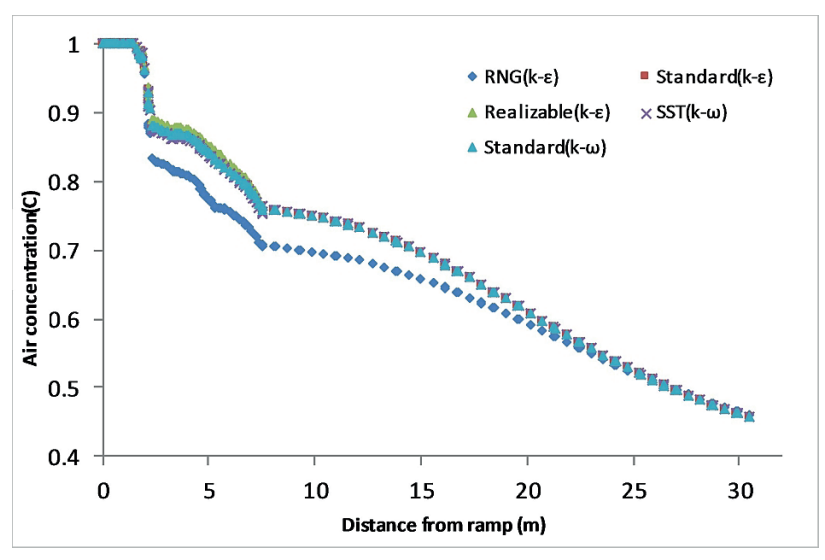

Fig. 13 Comparisons of bottom air concentration distribution obtained numerically using different turbulence models

of air concentration. These calculated values are more than the values produced by using the RNG $k-\varepsilon$ model for the majority of sections downstream of the aerator. Therefore, based on better performance of RNG model for determining the hydraulic characteristics of the flow, it can be concluded here that the chute models' bottom air concentration simulated by all the turbulence models, except the RNG $k-\varepsilon$ model, may be overestimated. Higher air concentration by other turbulence models compared with the RNG model can be seen from the area below air concentration profiles (average air concentration [4]) in Fig. 12. Estimating inaccurate bottom air concentration can result in an imprecise aerator geometry design to mitigate the cavitation damage. In this regard, it is necessary to assess and determine the most appropriate turbulence model for future numerical investigations.

\section{Conclusions}

Five numerical simulations of flow over Gavoshan spillway were carried out using different turbulence models to determine the optimum model. Flow characteristics, air cavity length, and air concentration distribution were estimated by these simulations. Various empirical equations for the cavity length estimation were assessed as the main factor of flow aeration. The most efficient turbulence model to simulate the free surface and velocity 
of the flow is the RNG k- $\varepsilon$ turbulence model. The RNG $k-\varepsilon$ and Standard $k-\omega$ models set the least and the biggest error percentage for flow depth, respectively. The standard $k-\omega$ model causes the maximum differences between numerical and experimental results. The accurate estimation for bed pressure resulted from RNG and realizable $k-\varepsilon$ turbulence models. The cavity lengths gained by applying RNG $k-\varepsilon$ model had a very small difference

\section{References}

[1] Yang, J., Teng, P., Zhang, H. "Experiments and CFD modeling of high-velocity two-phase flows in a large chute aerator facility", Engineering Applications of Computational Fluid Mechanics, 13(1), pp. 48-66, 2019.

https://doi.org/10.1080/19942060.2018.1552201

[2] Falvey, H. T. "Cavitation in Chutes and Spillways", Bureau of Reclamation, Denver, CO, USA, Engineering Monograph No. 42, 1990.

[3] Chanson, H. "Aeration and deaeration at bottom aeration devices on spillways", Canadian Journal of Civil Engineering, 21(3), pp. 404-409, 1994.

https://doi.org/10.1139/194-044

[4] Teng, P., Yang, J. "CFD modeling of two-phase flow of a spillway chute aerator of large width", Journal of Applied Water Engineering and Research, 4(2), pp. 163-177, 2016.

https://doi.org/10.1080/23249676.2015.1124030

[5] Kramer, K., Hager, W. H. "Air transport in chute flows", International Journal of Multiphase Flow, 31(10-11), pp. 1181-1197, 2005. https://doi.org/10.1016/j.ijmultiphaseflow.2005.06.006

[6] Pfister, M., Hager, W. H. "Chute Aerators. I: Air Transport Characteristics", Journal of Hydraulic Engineering, 136(6), pp. 352-359, 2010 .

https://doi.org/10.1061/(ASCE)HY.1943-7900.0000189

[7] Al Zubaidy, R. Z., Alhashimi, S. A. M. H. "Numerical Simulation of Two-Phase Flow over Mandali Dam Ogee Spillway", International Journal of Structural and Civil Engineering Research, 2(3), pp. 1-13, 2013. [online] Available at: http://www.ijscer.com/index. php? $\mathrm{m}=$ content $\& \mathrm{c}=$ index \&a $=$ show \&catid $=121 \& \mathrm{id}=14$

[8] Chinnarasri, C., Kositgittiwong, D., Julien, P. Y. "Model of flow over spillways by computational fluid dynamics", Proceedings of the Institution of Civil Engineers - Water Management, 167(3), pp. 164-175, 2014.

https://doi.org/10.1680/wama.12.00034

[9] Chakib, B. "Numerical Computation of Inception Point Location for Flat-sloped Stepped Spillway", International Journal of Hydraulic Engineering, 2(3), 47-52, 2013. https://doi.org/10.5923/j.ijhe.20130203.03

[10] Mu, Z., Zhang, Z., Zhao, T. "Numerical Simulation of 3-D Flow Field of Spillway based on VOF Method", Procedia Engineering. 28, pp. 808-812, 2013. https://doi.org/10.1016/j.proeng.2012.01.814

[11] Morales, V., Tokyay, T. E., Garcia, M. "Numerical Modeling of Ogee Crest Spillway and Tainter Gate Structure of a Diversion Dam on Cañar River, Ecuador", presented at XIX International Conference on Water Resources, Urbana, IL, USA, June, 17-22, 2012. from those of the experiment. The percentage of differences among other models was about $1 \%$ except for the Standard $k-\omega$ model which had an $8 \%$ difference with the SST $k-\omega$ model. Almost the same values of air concentration were extracted by various turbulence models except for the RNG $k-\varepsilon$ model which produced a small value. Nevertheless, overestimation of the bottom air concentration may affect the design of aerator devices.

[12] Tadayon, R., Ramamurthy, A. S. "Turbulence Modeling of Flows over Circular Spillways", Journal of Irrigation and Drainage Engineering, 135(4), pp. 493-498, 2009. https://doi.org/10.1061/(ASCE)IR.1943-4774.0000012

[13] Rahimzadeh, H., Maghsoodi, R., Sarkardeh, H., Tavakkol, S. "Simulating Flow Over Circular Spillways by Using Different Turbulence Models", Engineering Applications of Computational Fluid Mechanics, 6(1), pp. 100-109, 2012. https://doi.org/10.1080/19942060.2012.11015406

[14] Qian, Z. D., Hu, X. Q., Huai, W. X., Antonio, A. "Numerical simulation and analysis of water flow over stepped spillways", Science in China Series E: Technological Sciences, 52, pp. 1958-1965, 2009. https://doi.org/10.1007/s11431-009-0127-z

[15] Daneshfaraz, R., Joudi, A.R., Ghahramanzadeh, A., Ghaderi, A. "Investigation of flow pressure distribution over a stepped spillway", Advances and Applications in Fluid Mechanics, 19(4), pp. 811-822, 2016.

https://doi.org/10.17654/FM019040811

[16] Cheng, X., Chen, Y., Luo, L. "Numerical simulation of air-water two-phase flow over stepped spillways", Science in China Series E: Technological Sciences, 49, pp. 674-684, 2006. https://doi.org/10.1007/s10288-006-2029-2

[17] Kositgittiwong, D., Chinnarasri, C., Julien, P. Y. "Numerical simulation of flow velocity profiles along a stepped spillway", Proceedings of the Institution of Mechanical Engineers, Part E: Journal of Process Mechanical Engineering, 227(4), pp. 327-335, 2013. https://doi.org/10.1177/0954408912472172

[18] Yang, J., Teng, P., Lin, C. "Air-vent layouts and water-air flow behaviors of a wide spillway aerator", Theoretical and Applied Mechanics Letters, 9(2), pp. 130-143, 2019. https://doi.org/10.1016/j.taml.2019.02.009

[19] Jothiprakash, V., Bhosekar, V. V., Deolalikar, P. B. "Flow characteristics of orifice spillway aerator: numerical model studies", ISH Journal of Hydraulic Engineering, 21(2), pp. 216-230, 2015. https://doi.org/10.1080/09715010.2015.1007093

[20] Ozturk, M., Aydin, M. C. "Verification of a 3-D Numerical Model for Spillway Aerator", Mathematical and Computational Applications, 14(1), pp. 21-30, 2009. https://doi.org/10.3390/mca14010021

[21] Wu, J., Ruan, S. "Emergence Angle of Flow Over an Aerator", Journal of Hydrodynamics, 19, pp. 601-606, 2007. https://doi.org/10.1016/S1001-6058(07)60159-0

[22] Wu, J., Ruan, S. "Cavity length below chute aerators", Science in China Series E: Technological Sciences, 51, pp. 170-178, 2008. https://doi.org/10.1007/s11431-008-0009-9 
[23] Kökpınar, M. A., Göğüş, M. "High-speed jet flows over spillway aerators", Canadian Journal of Civil Engineering, 29(6), pp. 885$898,2002$.

https://doi.org/10.1139/102-088

[24] Water Research Institute "The Final Report of Discharge System of Gavoshan Storage Dam's Hydraulic Model", Ministry of Energy, Tehran, Iran, Rep. IH8123-FR, 2003.

[25] Kobus, H. "Local air entrainment and detrainment", In: Symposium on Scale Effects in Modelling Hydraulic Structures, Stuttgart, Germany, 1984, pp. 4.10-1-4.10-10. https://doi.org/10.18419/opus-559

[26] Boes, R. "Scale effects in modelling two-phase stepped spillway flow", In: Minor, H.-E., Hager, W. H. (eds.) Hydraulics of Stepped Spillways, Balkema, Rotterdam, Netherlands, 2000, pp. 53-60. https://doi.org/10.1201/9781003078609

[27] Hirt, C. W., Nichols, B. D. "Volume of fluid (VOF) method for the dynamics of free boundaries", Journal of Computational Physics, 39, pp. 201-225, 1981. https://doi.org/10.1016/0021-9991(81)90145-5

[28] Launder, B. E., Spalding, D. B. "Lectures in mathematical models of turbulence", Academic Press, London, UK, 1972.

[29] Yakhot, V., Orszag, S. A. "Renormalization group analysis of turbulence. I. basic theory", Journal of Scientific Computing, 1, pp. 3-51, 1986. https://doi.org/10.1007/BF01061452

[30] Shih, T.-H., Liou, W. W., Shabbir, A., Yang, Z., Zhu, J. "A new k-є eddy viscosity model for high Reynolds number turbulent flows", Computers and Fluids, 24(3), pp. 227-238, 1995. https://doi.org/10.1016/0045-7930(94)00032-T

[31] Wilcox, D. C. "Turbulence Modeling for CFD", DCW Industries, La Cañada Flintridge, CA, USA, 1993.
[32] Menter, F. R. "Two-Equation Eddy-Viscosity Turbulence Models for Engineering Applications", AIAA Journal, 32(8), pp. 1598-1605, 1994. https://doi.org/10.2514/3.12149

[33] Aydin, M. C., Emiroglu, M. E. "Determination of capacity of labyrinth side weir by CFD", Flow Measurement and Instrumentation, 29, pp. 1-8, 2013. https://doi.org/10.1016/j.flowmeasinst.2012.09.008

[34] Fluent Inc. "Fluent (6.3) User's Guide", 2006. [online] Available at: https://romeo.univ-reims.fr/documents/fluent/fluentGettingStarted. pdf

[35] Dargahi, B. "Experimental Study and 3D Numerical Simulations for a Free-Overflow Spillway", Journal of Hydraulic Engineering, 132(9), pp. 899-907, 2006. https://doi.org/10.1061/(ASCE)0733-9429(2006)132:9(899)

[36] Roache, P. J. "Perspective: A Method for Uniform Reporting of Grid Refinement Studies", Journal of Fluid Engineering, 116(3), pp. 405413, 1994. https://doi.org/10.1115/1.2910291

[37] Aydin, M. C. "CFD simulation of free-surface flow over triangular labyrinth side weir", Advances in Engineering Software, 45(1), 159166, 2012. https://doi.org/10.1016/j.advengsoft.2011.09.006

[38] Shayanseresht, S. "An Investigation of Hydraulic Characteristics of Flow on Large Dams' Spillways with Special Attention to Cavitation", MSc Thesis, Urmia University, 2014. (in Persian)

[39] Shayanseresh, S., Manafpour, M. "Investigation of Hydraulic Characteristics and Air Concentration of a 3DSimulated Air-Water Flow on a Spillway with an Aerator Device (A case study)", ISH Journal of Hydraulic Engineering, 2020. https://doi.org/10.1080/09715010.2020.1856732 